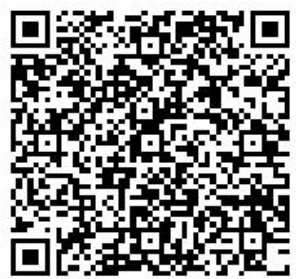

\title{
SOCIAL WORK SKILLS IN WORKING WITH SURVIVORS OF EARTHQUAKE
}

\section{Mohammad Reza Iravani*}

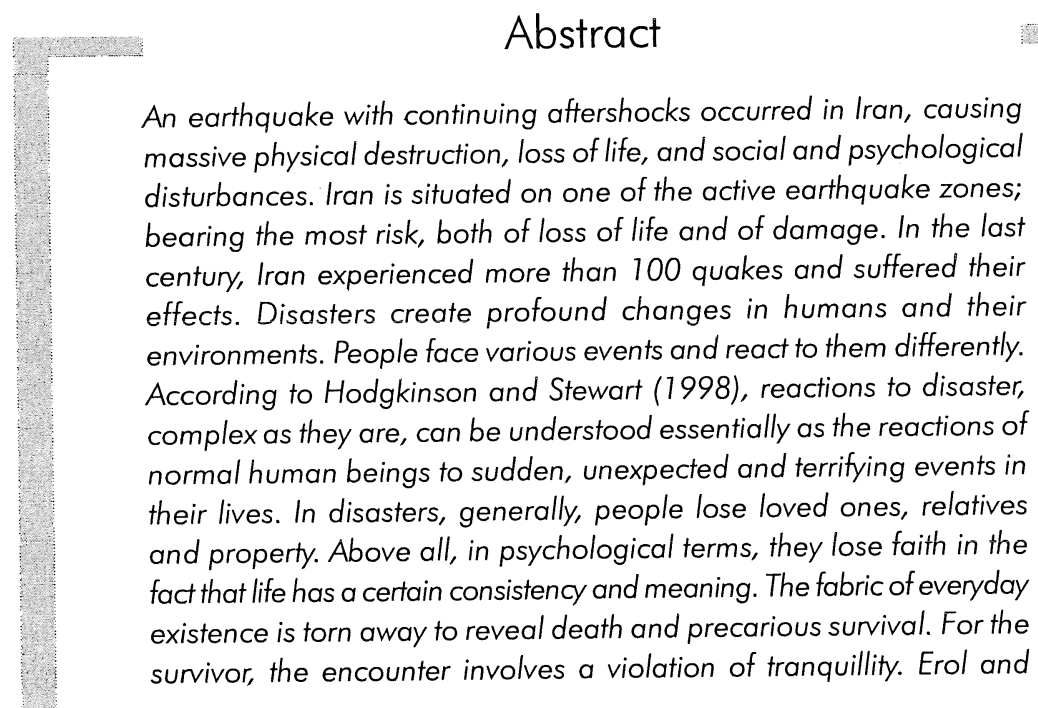

* Lecturer at Islamic Azad University Of Khomeinishahr (Iran), Islamic Azad University Khomeinishahr Branch, Daneshjou Blvd, E-mail: qqq200000@gmail.com 
Oner (1999) indicated that once a disaster has happened to individuals, they believe that life cannot ever be the same again; that they cannot go safely to bed at night and that they must have done something to deserve it. Thus they deal with the question of self-esteem and anxiety.

Keywords: earthquake, Survivors, destruction, Skills, Disaster, relief

\section{Introduction}

Humans have been coping with the effects of natural disasters and hazards throughout history and in every part of the globe. Both the impact of natural disasters and the ways in which humans have dealt with them have changed over time. This international conference brought together scholars from different disciplines to discuss the cultural strategies used to cope with floods, earthquakes, windstorms, and famine around the world from the Middle Ages to the present. Conference participants analyzed the different ways in which disasters were perceived and interpreted, the ways in which relief measures were organized, and the types of cultural strategies and coping mechanisms that evolved over time. For the first time, all of these issues were discussed in global and comparative perspective. One overarching question was whether national styles or cultural idiosyncrasies in dealing with disasters could be discerned.

Disaster relief is a complicated task that involves emergency and related services. Some of the relief work is done by social workers and should be acknowledged as part of social work practice and profession. Historically, social workers were involved in disaster relief work (Webster, 1995). However, this was not at the center of social work documentation and research (Streeter and Murty, 1996). Furthermore, disaster intervention is not always part of social work education. This article discusses the role of social workers in disaster situations. It is based on the Iran experience. Disasters affect the community at large. Consequently, human services have to address a variety of needs that emerge from the complex situation, whatever its causes are (Becker, 1997),. Following a disaster, rescue services are on the scene almost immediately and provide the specific operations they have been trained for. Upon completing their duties, they return to their bases. However, caring for the human outcomes of a disaster only begins. A closer analysis of what transforms a natural event into a human and economic disaster reveals that the fundamental problems of development that the region faces are the very same problems that contribute to its vulnerability to the catastrophic effects of natural hazards. The 
principal causes of vulnerability in the region include rapid and uncontrolled urbanization, the persistence of widespread urban and rural poverty, the degradation of the region's environment resulting from the mismanagement of natural resources, inefficient public policies, and lagging and misguided investments in infrastructure. Development and disaster-related policies have largely focused on emergency response, leaving a serious under investment in natural hazard prevention and mitigation. A proactive stance to reduce the toll of disasters in the region requires a more comprehensive approach that encompasses both pre-disaster risk reduction and post-disaster recovery.

Less than ten days ago, a deadly earthquake devastated the Iranian city of Bam, killing more than 30,000 people and injuring another 50,000. It was one of the deadliest natural disasters in modern Iranian history, and similar in destruction to the Roudbar earthquake in northern Iran in 1990. Historical information and all available records show that approximately 130 large earthquakes have taken place in most parts of Iran. Considering the high seismi city of Iran, a comprehensive hazard reduction program was launched in Iran in 1991, but the effectiveness of the measures have been limited by lack of adequate funding and institutional coordination. There is no lack of probabilistic studies on the seismicity of the country as well as fault studies.

\section{Earthquakes: The Most Destructive Force of Nature}

Earthquakes are the most destructive among all the natural hazards. Most of the time, they occur without any warning, which makes them most feared and unpredictable natural phenomena. Globally, on an average two earthquakes of magnitude 8 are known to occur every year. Iran is surrounded by tectonically active zones. Earthquakes are regularly felt on all sides of Iran. But the capital, Tehran, has been fortunate enough to avoid a major quake this century. Tehran was shaken in 1830 by a magnitude 7.2 quake.

\section{Earthquakes: Causes}

The true nature of the causes of an earthquake must be fairly well understood before adopting any control measure. Two models are being tested to justify these control measures.

1. Dilatancy-diffusion theory developed in the U.S.

2. Dilatancy-instability theory USSR 
The first stage of both models is an increase of elastic strain in a rock that causes them to undergo adilatency state; which is an inelastic increase in volume that starts after the stress on a rock reaches one half its breaking strength. During Dilatancy State, open fracture developing the rocks. So it is in this state the first physical change takes place indicating future earthquake. Here the two models diverge. The U.S. model suggest that the dilatancy and fracture of the rocks are first associated with a low water containing dilated rock, which helps in producing lower seismic velocity, lower electrical resistively and fewer minor seismic event. The pore water pressure then increases due to influx of water into the open fracture, weakening the rock and facilitating movement along the fracture, which is recorded as an earthquake.

In contrast the Russian model state that the first phases is accompanied by an avalanches of fracture that release some stress but produce an unstable situation that eventually cause a large movement along a fracture. Seismic gaps are defined as an area along active fault zones, capable of producing large earthquake but that have not recently produced an earthquake. These areas are thought to store tectonic strain and thus are candidate for future large earthquake. Any fault that has moved during quaternary can be called as active fault. It is generally assumed that these faults can get displaced at any time. Faults that have been inactive for the last three million years are generally classified as inactive fault. Active faults are basically responsible for seismic shaking and surface rupture (Sinha et al. 2000) Like all other natural hazards earthquakes also produce primary and secondary effects. Primary effects include surface vibration, which may be associated with surface rupture and displacement along fault plane. These vibrations may sometimes lead to the total collapse of large buildings, dams, tunnels, pipelines and other rigid structures. Deterministic ground motion analysis is one of the tools to determine the spatial distribution of surface vibration. Secondary effects of earthquake include a variety of short-range events; such as liquefaction, landslides, fires, tsunamis and floods. Long-range effects include regional phenomena such as regional subsidence or emergence of landmasses, river shifting and regional changes in ground water level.

Disaster research in social work has deep roots in the profession's history of disaster relief, social work's mission to create resources and make them accessible to people, and the profession's service to vulnerable populations. Social workers have important and unique contributions to make to disaster research through their expertise in ecological approaches, prevention, stress and coping, and promoting change in micro and macro systems. Disaster research in social work borrows primarily from psychology and sociology, and is conducted in clinical, organizational, and community contexts. Further social work research on disaster promises improved theory, measurement, and practice in situations of collective stress. 


\section{Social work contacts}

Social workers seem to be the only professionals who are represented at almost every site that is directly or indirectly linked to the disaster. Contacts between people in need and social workers can begin early. Some begin on site. An initial encounter made during an emergency can develop into a helping contact (Seroka et al., 1986). In some cases, victims and their families may ask the worker who met and helped them on site to continue seeing them. The fact that this social worker was together with the family during its worst moments may help establish a unique professional bond. This of course reassures the family not only of the continuity of the process, but also of being able to rely on a professional who knows the case, and by virtue of the tragedy has become a partner. Indeed, a pertinent question often raised is whether the public will accept social workers intervening in emergencies. Dealing with crisis counseling, Stewart (1989) discusses issues related to selling social work to the community. Traditionally, 'to be associated with social work is to be associated with failure and low status . . . those working with survivors of disaster have to confront this handicap'. However, in an emergency, people may have to approach social workers, or accept their outreach efforts. Evaluating these efforts after the Lockerbie disaster (1988), it was argued that despite the tragic circumstances 'the residents don't understand social work, and are aware of the stigma attached to utilizing the services of a social worker'. In Iran such reactions have been monitored. On the contrary, the public image of social workers seems to change and their central role in disaster work is acknowledged.

The Iran experience shows that social workers are the professionals best prepared to deal with complex situations resulting from an emergency. First, they have the basic training enabling them to relate to the needs of individuals, families and groups. Second, most social workers have some knowledge and experience in crisis intervention, family dynamics and loss. Third, most social workers are well informed about existing welfare programs and services and can refer people to other agencies for specialized help. Fourth, employed in a large variety of agencies, including hospitals, schools, community facilities and even private and public work places, social workers can easily make contacts, becoming an invaluable helping network. Forming such a network is an essential partnership in facilitating professional, comprehensive emergency relief work. This network is based on formal and informal ties between members of the same profession who know and trust each other. When this is the case, even sensitive information can be exchanged, formally and informally, within this network. A social worker stationed at one location may contact her/his colleague and refer a worried relative to that colleague. Having a contact person is reassuring and helpful. Social workers assigned by JET to various stations are equipped with sophisticated communication devices, enabling 
them to broadcast into the JET radio network and provide everyone with valid information. For sharing more personal information, the same device also serves as a cellular phone. Social workers can therefore share information and contact people personally. Such contacts are important as they help social workers collect and exchange personal concerns and worries. They also help social workers support each other when they themselves feel anxious or depressed.

\section{Politics and victims}

In the aftermath of the earthquake, as I have described it, the state began to impinge on freedoms and autonomy. It took an iron grip by divesting people of property and their property rights and investing heavily in a superabundance of new bureaucracy, which was often uncertain of its proper relationship with the preexistent bureaucracy. The government became a source of worry and confusion for many people and, as the nostalgia inherent in the separatist agitations reveals, it also became a target for their anger. But there was a glaring paradox here. On the one hand, people were clearly alienated from the government and from their natural and social environments, often quite literally so, and they publicly resented this. On the other hand, the compensation schemes promise dwealth. As a result, access to the government is coffers became highly competitive and a source of jealousy, rivalry and suspicion. In time, the struggle for compensation became a collective preoccupation pursued along non-collective lines. Once the levels and nature of the compensation had been set, there was little option for most people but to claim as much as possible. Any claim was time-consuming, and involved large numbers of documents and numerous trips to various government offices. The amounts available were as large as the levels of corruption that surrounded their distribution.

The social ethics of relief giving (the bases on which relief ought to be given) in natural disaster situations are explored through a case study of public reactions to Red Cross activities. Red Cross policies \& public reactions to them are reviewed, \& survey data pertaining to attitudes toward the Red Cross \& toward relief giving in natural disasters of residents of a western NY county are presented. Specifically, public satisfaction with present Red Cross distribution policies is explored, \& public perceptions of "loss vsneed" as bases for relief giving are examined. Although there are some qualifications, findings show a large segment of the public supporting bases other than "need" for the distribution of disaster aid. Implications are that the public does not always support are distributive role for relief giving, but in some cases, with some populations, expects relief giving to reinforce the status quo.

In the early days after the earthquake local people were not involved in the decision making and pre-existing support networks were not utilized. Given that nearly two- 
thirds of the population were either killed or injured in the earthquake, it is not surprising that external agencies found it difficult to identify what remained intact in terms of formal and informal networks. While acknowledging that re-creating social capital is no simple task, Putnam (2000: 402) asserts that a palpable national crisis such as a natural disaster can make the task easier. However, the sense of national solidarity reported in the Iranian media was only temporary and gradually the survivors began to feel disenfranchised and mistrustful of relief efforts coordinated by non-Bamis. Before the earthquake, Bamhad been an affluent city, the regional centre for date growing and packing. Yet in the space of just a few minutes, this physical capital was destroyed and the people of Bam were dependent on others to assist them. Genuine survivors of the earthquake found that their immediate needs were not being met because of the rapid poor people from the surrounding unaffected area claiming relief food and goods. Due to the poor construction of the buildings in Bam, there were few human survivors, but even so, there were insufficient tents and blankets to protect them from the severe cold of the Iranian winter. Donated tents subsequently arrived, but many survivors preferred to remain among the debris of their former home to protect it from looting. The key social capital ingredients of trust, mutuality and reciprocity present previously in the city of Bam were becoming less evident in the region at both micro and meso levels. Individuals were needed at this stage to bridge communities and link survivors in an organized fashion with those from outside Bam who were in a position to help. A week after the earthquake struck, the of. cial relief effort was still not fully organized or coordinated, a task that should have been undertaken by the regional governor of Kerman Province.

\section{Social work functions in disaster aid have been summarized as follows (Yueh, 2003).}

1. Supporting individuals and families. In Bam this included: providing emotional support, grief counseling and post-disaster support (PTSD) for vulnerable groups like people with disabilities, children and elderly people; motivating victims to join activities; providing emotional support for families in shelters; helping families to arrange for funerals and build tents; visiting homes; and interviewing families of the victims.

2. Linking individual needs with resources and helping people to access resources. This included facilitating contact between local government and voluntary groups; linking social services with the needs of the people; identifying vulnerable people; linking family needs with resources and .ending these; collecting donations; collecting, delivering and distributing food and materials; and registering the needs of victims for central government officers. 
3. Preventing severe physical and mental problems. These included therapeutic interventions for survivors, including various types of counseling, e.g. grief counseling and post-relief counseling, linking patients to therapists and therapeutic centers.

4. Preventing individuals, families, groups, organizations and communities from breaking down. This included providing accommodation, information and support to individuals and families who were homeless; reducing survivors' lack of interest in life, and feelings of powerlessness and despair; coordinating and organizing responses to groups, agencies and communities effectively.

5. Intervening to change micro and macro systems to improve client well-being. This included advocating for change in governmental programs; developing volunteer services; conducting needs assessments; improving service programs; providing distribution centers for the victims; changing welfare policies and recovery programs to improve a community's ability to meet people's needs; developing the capacity of systems to improve the inferior structural status of earthquake victims.

Many countries lie in an earthquake zone. Excluding the Bam earthquake, the nine biggest quakes in Iran during the last century measured 5.2-7.3 on the Richter scale and caused anything between 450 and 40,000 fatalities (Goudarzi, 2004). Despite this, neither social work educators nor practitioners created a specialism on disaster programming. The available literature can help social workers learn what it is possible and/or necessary to do when delivering assistance programs as part of a rescue team giving disaster relief aid. Social workers are an important part of disaster aid and recovery plans at the micro, mezzo and macro levels. They play key roles in earthquake relief by assisting earthquake survivors and are on the frontline of emergency responses, as they were in the Bam earthquake. There, they not only acted as representatives of the state, but they also joined families who were waiting to pull survivors from the debris, provided emotional support for families in shelters and helped families arrange funeral ceremonies. As government agents, social workers act on its behalf during emergency relief and thus enable it to carry out its responsibilities through their work.

\section{Recommendations}

Based on our experience of working in the disaster stricken area, the following recommendations are made to address the subject of caring for those social workers who are deputed to perform relief work in disaster areas: 
1. Timely rotation of care providers at regular intervals;

2. Focused briefing about the objectives and role of the care provider in relation to the task ahead;

3. The managers must ensure proper logistic support of the project;

4. A debriefing of the individual care provider and the whole team when relief and support duties have been completed;

5. A break or time off for the care provider, or at least relaxed duties after completion of their duties; and

6. Expressions of appreciation from the management and judicious granting of rewards.

One important implication concerns the channeling of resources to reduce exposure to stress and the resulting consequences. Support and counseling schemes targeted at traumatic stress or provision of additional staff, resources, or reduced workloads should be provided to reduce organizational stresses. Employee assistance programs with individualized interventions, monitoring, and more effective pre-employment screening may be a sound policy. With stress resulting from disaster responses potentially influencing the way an individual perceives and/or copes with subsequent negative life events, practitioners providing services to disaster or rescue workers can encourage their clients to monitor their levels of stress and the ways that they care for themselves both during and following disaster assignments.

The curriculum related to disaster aid services and practices should be studies in social work departments at universities both in Iran and indeed in most other developing countries. Natural disasters such as typhoons, .goading and earthquakes are happening frequently and are even getting worse. Social workers need to face up and react to this reality as future members of a team that will work on disserts relief. I recommend that instructors allocate one or two sections of their social work curriculum (about 15-20 sessions) to discussing disaster responses. These should include how social work students work with survivors, their families and communities; how they apply for all sorts of resources needed by victim survivors, how they help remaining family members cope with the death of other family members and make funeral arrangements. Furthermore, the student's practicum should also emphasize this type of social work and provide opportunities for working through some of the issues of disaster relief operations. 


\section{Role of the NGOs in addressing disasters effectively}

1. Rehabilitation of neglected children, orphan children \& the community at large in coping with the consequences of disaster

2. Enhancing community's capacities to cope with the future disasters

3. Investing in people's knowledge-building rather than just physical infrastructure

4. Improving livelihood options, empowering individuals, so that they can meet their own needs

5. Strengthening local institutions using local resources, \& transferring appropriate technologies

\section{Conclusions}

Since the earthquake disaster affected entire communities, children's families, teachers and friends were also victims. The Pynoos etal. (1993) study, with earthquake survivors among Armenian children, documented that the impact of a major catastrophe might directly affect an entire child population of a large area. The psychological sequel of this magnitude of disaster may alter the individual and social character of a whole generation of children and their families, and PTSD rates may reach epidemic proportions. Chronic, severe and high prevalence rates of PTSD found in this study of Turkish children support this conclusion. Moreover, professional help was also limited; 69 percent reported that they had not received any psychological or educational debriefings or any type of individual or group counseling, and 45 percent felt they might need counseling. Survivor children developed earthquake related cognitive and physical avoidance: Traumatized children did not want to go to places which reminded them of the earthquake and did not want to see people or survivors who would talk about earthquakes. This phenomenon, that survivors might develop numbing and effortful avoidance, has been previously reported by Foa et al. (1995). Clinicians working with an exposed or at-risk population should consider the nature of chronic severe and high epidemiological rates of PTSD when planning intervention and prevention programs.

Social workers are required to cope with a variety of duty related stresses, including the exposure to traumatic incidents. A cornerstone of the effectiveness of mental health support at the scene of operations is establishing a rapport between the mental health team and the command staff, rescue team managers, and social workers. Disasters workers have a deep commitment to working long hours without breaks, and quickly may dismiss suggestions about using time to relax. Understanding 
the stressors associated with rescue work and its culture can facilitate alliance building. Social workers often have a high capacity for trust among each other, but they tend to be cautious about the competencies of individuals perceived as outsiders. Rescue workers may demonstrate mental and emotional resilience during an operation, but they may have intense emotional reactions afterwards because of their sensitivity to the suffering of survivors and their families. If social workers tactfully acknowledge this duality, it would help them to achieve the confidence of rescue workers while increasing the workers' willingness to disclose feelings of vulnerability or self-criticism, and to accept emotional support.

\section{References}

Asian Development Bank and World Bank: Pakistan 2005 earthquake: Preliminary damage and needs assessment. Available at http://www.pakistan.gov.pk/divisions/economicaffairsdivision/media/MAIN-TEXTNOV-11.pdf. Accessed 25 September 2007.

Figley CR, Kleber RJ: Beyond the "Victim": Secondary Traumatic Stress. In : Kleber 14. Bramsen I, Dirkzwager AJE, van der Ploeg HM: Predevelopment personality traits and exposure to trauma as predictors of posttraumatic stress symptoms: A prospective study of former peacekeepers. Am J Psychiatry 2000;157:1115-1119.

Alexander DA, Wells A: Reactions of police officers. 